OCCASIONAL REVIEW

\title{
Effect of treatments on the progression of COPD: report of a workshop held in Leuven, 11-12 March 2004
}

\author{
M Decramer, R Gosselink, P Bartsch, C-G Löfdahl, W Vincken, R Dekhuijzen, J Vestbo, \\ R Pauwels, $†$ R Naeije, T Troosters
}

Thorax 2005;60:343-349. doi: 10.1136/thx.2004.028720

During the last decade several long term studies of interventions in patients with COPD have been published. This review analyses the potential of these interventions to alter the progression of the condition. The only treatment that has unequivocally been shown to reduce the rate of decline in $\mathrm{FEV}_{1}$ is smoking cessation. Active psychological intervention in combination with pharmacotherapy is required. Other treatments may have an effect on the rate of decline in $\mathrm{FEV}_{1}$ but this appears to be very small, at most. Several treatments affect the exacerbation rate and therefore might affect the progression of the disease. Further studies are warranted to examine this effect.

See end of article for authors' affiliations authers affiliations

Correspondence to: Professor M Decramer, Respiratory Division, University Hospital, Herestraat 49, 3000 Leuven, Belgium; Marc. Decramer@uz.kuleuven. ac.be

Received 18 May 2004 Accepted 24 January 2005
D uring the last years insight into the progression of chronic obstructive pulmonary disease (COPD) has increased considerably. This insight is largely derived from four large scale and long term studies on the effects of inhaled corticosteroids, ${ }^{1-4}$ and from large scale 1 year studies with tiotropium ${ }^{5} 6$ and with the combination of long acting $\beta_{2}$ agonists and inhaled corticosteroids. ${ }^{78}$ These studies have unravelled a number of methodological problems associated with large scale long term studies which form the basis of the accompanying paper on assessment of progression of COPD. ${ }^{9}$ They also provided important information on the treatment of COPD and, as such, form the basis of current treatment and the widely used GOLD guidelines. natural course of COPD have been examined in a number of large scale trials. Although the outcome of these has been negative in terms of affecting the progression of COPD, these trials have substantially enhanced our understanding of the natural evolution of the disease and the potential for effects of treatments. These trials unfortunately focused on patients with irreversible COPD, which was an important bias against observing an effect. Moreover, although the outcomes were largely negative in terms of affecting the progression of COPD as estimated by the annual decline in forced expiratory volume in 1 second $\left(F_{E V}\right)$, there are several indications that treatments may affect variables that may be related to or affect the progression of COPD. They may therefore form the basis of research addressing this important question in the future.
The effects of several treatments on the
The purpose of this paper is to review the potential of several treatment options available to patients with COPD to alter the natural course of the disease. The assessment of progression of COPD has been dealt with in a separate paper. ${ }^{9}$ This review will deal with the effects of intervention on the progression of COPD and discuss all the interventions that have been studied during the last decade. These include smoking cessation, long acting $\beta_{2}$ agonists, long acting anticholinergic agents, inhaled steroids, combination products, antioxidants, and rehabilitation. For each of the treatments the potential of affecting the progression of COPD as discussed in the accompanying paper ${ }^{9}$ —in terms of affecting the annual decline in $\mathrm{FEV}_{1}$, decline in health status, exacerbation rate, and mortality-will be highlighted. Effects on decline in functional status will only be discussed with rehabilitation as no data are currently available with other treatments. Effects on the increase in healthcare costs will not be discussed as at present only scanty data are available in this field.

Most of the effects shown by treatments are related to an effect on exacerbation rate. As discussed in the accompanying paper, ${ }^{9}$ exacerbations are really central to the progression of COPD. They are related to the decline in $\mathrm{FEV}_{1}{ }^{10}$ progressive decline in health status, ${ }^{11}{ }^{12}$ increased costs and hospitalization, ${ }^{9}$ and decline in functional status. ${ }^{13}$ As COPD worsens, the frequency and severity of exacerbations might increase. ${ }^{12}$ As will be discussed in this review, several treatments have been shown to have an effect on exacerbation rate.

\section{SMOKING CESSATION}

It has been clear for almost half a century that the main cause of COPD is smoking. It has become evident in the last decade that the most efficient treatment against COPD progression is smoking cessation. Two studies are of pivotal importance in this field. The first is the study by Doll et al on British doctors published in 1994 after 40 years of observation. ${ }^{14}$ The second is the Lung Health Study (LHS), ${ }^{15}$ a 5 year randomised

Abbreviations: COPD, chronic obstructive pulmonary disease; $\mathrm{FEV}_{1}$, forced expiratory volume in 1 second; FRC, functional residual capacity; ICS, inhaled corticosteroids; LAAC, long acting anticholinergics; LABA, long acting $\beta_{2}$ agonists; $6 M W D$, six minute walking distance; NAC, N-acetylcysteine; ROS, reactive oxidant species

${ }^{\dagger}$ Deceased. 
trial which started in the US in 1986. This massive multicentre trial (nine US and one Canadian centres) enrolled 5887 adult smokers with mild to moderate COPD $\left(\mathrm{FEV}_{1} 55-90 \%\right.$ of predicted). Two thirds of the original participants were offered an intensive 12 week smoking cessation intervention. The British survey showed us the natural history of smoking in a selected population and the American trial demonstrated the effects of a specific smoking cessation intervention on the history of COPD among smokers who quit, tried to quit, or never quit. The study by Doll et al has shown that, besides lung cancer, smoking caused COPD and reduced life expectancy among doctors. ${ }^{14}$

This was shown to be true for less selected people as well. Fletcher et $\mathrm{al}^{16}$ showed that up to $26 \%$ of heavy smokers developed COPD among workers in London. Moreover, as the prevalence of smoking is rising in women and slightly decreasing among men, the sex distribution of COPD has shifted from $19 \%$ women in 1970 to $38.5 \%$ in $1993^{17}$ and almost $50 \%$ in $2000 .{ }^{18}{ }^{19}$

The Lung Health Study I (LHS I) has extensively demonstrated the efficacy of an intensive smoking cessation

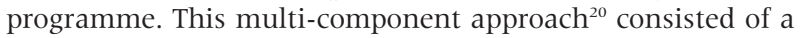
cognitive-behavioural strategy including stimulus control, avoidance, role playing, assertiveness, training, reinforcement and relaxation techniques. The intervention group also received polacrilex nicotine $2 \mathrm{mg}$ gum. The number of pieces of gum used by ex-smokers was $8-11$ and less than 8 by continuing smokers. No cardiovascular illness or other serious side effects were reported. ${ }^{21}$ The validated (exhaled carbon monoxide and/or salivary cotinine level) 5 year sustained cessation rate was $22 \%$ in the intervention group compared with only $5 \%$ in the usual care group. ${ }^{22}$ Ipratropium bromide had no effect on the decline in $\mathrm{FEV}_{1} \cdot{ }^{23}$

A follow up study at 11 years $^{24}$ showed that $93 \%$ of participants who refrained from smoking throughout the LHS were still abstinent after this long period. At that time, $38 \%$ of continuing smokers had an $\mathrm{FEV}_{1}$ less than $60 \%$ of predicted compared with $10 \%$ of sustained quitters. The subgroup of intermittent smokers/quitters was also evaluated. Surprisingly, those who made several attempts to quit smoking had a smaller decline in lung function at comparable cumulative doses of cigarettes than those who continued to smoke. ${ }^{25}$ The fall in $\mathrm{FEV}_{1}$ was $0.23 \%$ predicted $(27 \mathrm{ml})$ per year for quitters, $0.91 \%$ predicted $(48 \mathrm{ml})$ per year for intermittent smokers, and $1.29 \%$ predicted $(60 \mathrm{ml})$ per year for continuing smokers. Analysis by sex in the LHS showed that, among those with mild COPD, women appeared to benefit more from smoking cessation than men. ${ }^{26}$

The results of the LHS showed that smoking cessation is an effective way of altering the progression of COPD. Moreover, it is the only treatment that does this, in contrast to bronchodilators and inhaled corticosteroids (see below). We may assume from the LHS that any psychological and/or pharmacological approach of smoking cessation that gives a $\pm 22 \%$ smoking cessation rate at 1 year among patients with mild to moderate COPD would achieve the same effects on lung function. The number of randomised studies on smoking cessation in patients with COPD is small; the results can be extrapolated from general population trials.

\section{PHARMACOLOGICAL TREATMENT Long acting $\beta_{2}$ agonists}

Bronchodilators are effective in the symptomatic treatment of COPD, and the main classes for maintenance treatment are anticholinergic agents and long acting $\beta_{2}$ agonists (LABA). It is well established that LABA decreased symptoms such as breathlessness and daytime as well as night time symptoms in COPD. ${ }^{27-29}$ In addition, LABA have shown improvement in health status in some studies. ${ }^{30}$ Surprisingly, there was no clear dose-response effect. ${ }^{28}{ }^{30}$ In recent studies where LABA have been compared with combination treatment there is some evidence that LABA as a single treatment may have a positive effect on health status. ${ }^{71}$ Studies on exercise capacity have also shown some evidence of improvement, but in long term studies the effect was small and often not significant. Surprisingly, a recent study with formoterol showed an inverse dose-response effect on exercise capacity. ${ }^{32}$

Whether LABA might affect disease progression is unclear. Firstly, there are no long term data showing an effect on mortality in COPD. Soriano and coworkers ${ }^{33}$ compared salmeterol treatment with a reference treatment in patients from general practices in the UK and found no indication of an effect on mortality. In contrast, inhaled corticosteroids as well as inhaled corticosteroids in combination with LABA were associated with a significantly lower mortality rate. ${ }^{33}$ Secondly, an effect on the long term decline in $\mathrm{FEV}_{1}$ has not been shown with LABA, but no studies have specifically addressed this question. There are few data comparing regular treatment with $\beta$ agonists with on demand treatment showing that, in a 4 year perspective, these treatments did not differ in their effect on the decline in $\mathrm{FEV}_{1} \cdot{ }^{34}$ One year trials with outcomes other than the decline in $\mathrm{FEV}_{1}$ have not shown any reduction in deterioration with LABA treatment. $^{7831}$

The question then arises whether it is theoretically possible that LABA could have a long term effect on the progressive deterioration in COPD. There are in vitro data indicating that LABA has anti-inflammatory effects, and no effect has so far been shown on the neutrophilic inflammation typical of COPD. ${ }^{35}$ An anti-oedema effect with LABA has been described in guinea pigs. ${ }^{36}$ Furthermore, salmeterol was shown to increase mucociliary clearance in normal subjects and in patients with bronchitis. ${ }^{35}$ However, at present none of these effects have been clearly shown to be present in patients with COPD and no effect on outcome variables has been seen in these patients.

Exacerbations are important in COPD and have a slight influence on the long term development of deteriorated airway function, together with a clear impact on the health status of the patients. Table 1 provides an overview of the effects of different treatments on the annual exacerbation rate in COPD. There is evidence that LABA could decrease the number of exacerbations. This is quite well shown for mild exacerbations but the evidence is scarce for an effect on severe exacerbations-that is, exacerbations leading to intervention with other treatment. ${ }^{783137}$ The TRISTAN study showed an effect with salmeterol alone with a significant decrease of $20 \%$. The effect was more pronounced in the more severe group with $\mathrm{FEV}_{1}$ below $50 \%$ predicted. ${ }^{8}$ No clear explanation for these observations is available. A potential explanation could be that LABA have a protective effect against damage in the mucosa by bacterial toxins. ${ }^{38}$ Together with inhaled corticosteroids, salmeterol has been shown to have a synergistic effect with fluticasone on bacterial colonisation. ${ }^{39}$ Formoterol also has a pro-inflammatory inhibitory effect in combination with a corticosteroid..$^{40}$

\section{Long acting anticholinergics}

The long acting anticholinergic (LAAC) tiotropium bromide has recently become available. Two long term studies ( 1 year) of tiotropium versus placebo ${ }^{5}$ and ipratropium, ${ }^{6}$ respectively, have shown clinically beneficial effects on pulmonary function (without tolerance/tachyphylaxis developing), dyspnoea scores, use of rescue short acting $\beta$ agonists, health related quality of life, COPD exacerbations, and hospital admissions for exacerbations (table 1). The additional costs of substituting tiotropium for ipratropium to achieve these favourable outcomes were estimated at $€ 180$ per patient per 
Table 1 Percentage reduction in annual exacerbation rate in major studies

\begin{tabular}{|c|c|c|c|}
\hline Study & Reference & Treatment & Effect (\%) \\
\hline EUROSCOP & Pauwels et al" & Budesonide/placebo & 0 \\
\hline ISOLDE & Burge et $a^{\beta}$ & Fluticasone/placebo & 25 \\
\hline Copenhagen City Lung Study & Vestbo et $a P^{2}$ & Budesonide/placebo & 0 \\
\hline LHS II & LHS Group ${ }^{4}$ & Triamcinalone/placebo & - \\
\hline TRISTAN & Calverley et $a^{\beta}$ & Comb/placebo & 25 \\
\hline \multirow[t]{2}{*}{ Symbicort } & Szafranski et aP & Comb/placebo & 24 \\
\hline & Calverley et $a^{\beta}$ & Comb/placebo & 23 \\
\hline \multirow[t]{2}{*}{ Tiotropium } & Vincken et $a^{5}$ & Tiotropium/ipratropium & 24 \\
\hline & Casaburi et al & Tiotropium/placebo & 20 \\
\hline BRONCUS & Decramer et $\left.a\right|^{\beta 0}$ & NAC/placebo & 22 \\
\hline Rehabilitation & Griffiths et $\left.a\right|^{\beta 2}$ & Rehabilitation/placebo & 26 \\
\hline
\end{tabular}

year. ${ }^{41}$ Currently, a 4 year maintenance treatment study comparing tiotropium with placebo in COPD patients (the UPLIFT study) is being conducted to assess its effect on the long term decline in lung function as well as on the morbidity and mortality rates. There are at least three indirect indications that signal the potential of tiotropium as a disease modifying agent. In the 1 year trials the decline in trough $\mathrm{FEV}_{1}$ was around $40 \mathrm{ml} /$ year in the placebo group compared with about $10 \mathrm{ml} /$ year in the tiotropium group. ${ }^{6}$ This may be due to residual bronchodilation lasting longer than 24 hours as the difference was substantially smaller if postbronchodilator $\mathrm{FEV}_{1}$ was considered. Tiotropium was shown to reduce the exacerbation rate and-in as much as exacerbations are related to the annual decline in $\mathrm{FEV}_{1}{ }^{11}{ }^{42}-\mathrm{a}$ reduction in the latter may be expected. Finally, the rate of deterioration in health status after an initial improvement appeared less with tiotropium than with ipratropium. ${ }^{5}$

\section{Inhaled steroids}

Data from early studies on the effects of inhaled corticosteroids (ICS) on the decline in $\mathrm{FEV}_{1}$ are limited and leave much room for different interpretations. Kerstjens et $a l^{43}$ showed an effect on both $\mathrm{FEV}_{1}$ and exacerbations. Less distinction between asthma and COPD was made than would be considered right according to present COPD guidelines. Distinction between asthma and COPD was more obvious in the smaller study by Renkema et $a^{44}$ from 1996. Their study showed some effect of ICS on $\mathrm{FEV}_{1}$ but the power of the study was too limited. A pooled study by van Grunsven et a l $^{45}$ of the patients from the studies by Kerstjens et $a l^{43}$ and Renkema et al, ${ }^{44}$ together with a study published only as an abstract, ${ }^{46}$ has been published. This analysis showed an estimated 2 year difference in pre-bronchodilator $\mathrm{FEV}_{1}$ between subjects treated with ICS and placebo of $34 \mathrm{ml} / \mathrm{year}$. This was statistically significant in spite of the fact that approximately one third of the originally included patients were excluded from the pooled analysis. ${ }^{45}$ The effect on postbronchodilator $\mathrm{FEV}_{1}$ was less impressive and the time course of $\mathrm{FEV}_{1}$ did not fit with our general understanding of the time course of the decline in $\mathrm{FEV}_{1}$ in COPD. In a smaller Canadian study of 77 patients with COPD irreversible to systemic corticosteroids, Bourbeau et $a l^{47}$ found no effect of inhaled budesonide $1600 \mu \mathrm{g}$ daily on $\mathrm{FEV}_{1}$, dyspnoea, or exercise capacity.

Four large placebo controlled trials of ICS in COPD have been conducted. The Copenhagen City Lung Study (CCLS) ${ }^{2}$ included 290 subjects with predominantly mild COPD from an ongoing epidemiological study. Patients were non-asthmatic subjects with a ratio of $\mathrm{FEV}_{1}$ to vital capacity (VC) of $<0.7$, irreversible to oral prednisolone and inhaled terbutaline. A total of 290 patients were randomised to either budesonide $(800+400 \mu \mathrm{g}$ daily for 6 months followed by $400 \mu \mathrm{g}$ twice a day for 30 months) or placebo for 36 months.
The study drug and placebo were given in the Turbuhaler. The mean age was 59 years, mean $\mathrm{FEV}_{1}$ was 2.37 litres $(86 \%$ of predicted), $40 \%$ were women, and $77 \%$ were present smokers. The main outcome parameter was decline in $\mathrm{FEV}_{1}$, and crude declines in $\mathrm{FEV}_{1}$ turned out to be slightly smaller than expected (42 ml/year in the placebo group and $45 \mathrm{ml} /$ year in the budesonide group). Using a regression model in the intention-to-treat population, patients in the placebo group had a decline in $\mathrm{FEV}_{1}$ of $49 \mathrm{ml} /$ year compared with $46 \mathrm{ml} /$ year in the budesonide group; the estimated difference $3.1 \mathrm{ml} /$ year (95\% confidence interval -12.8 to 19.0 ) was both statistically and clinically insignificant $(p=0.70)$. There was no initial rise in $\mathrm{FEV}_{1}$ in the budesonide group. No effect was seen on exacerbation rate.

The European Respiratory Society Study on Chronic Obstructive Pulmonary Disease (EUROSCOP) ${ }^{1}$ was a multicentre European study. EUROSCOP included patients with mild COPD who continued to smoke in spite of a 3 month smoking cessation programme including nicotine gum. A total of 1277 current smokers were randomised to either budesonide $400 \mu \mathrm{g}$ twice daily or placebo, both given by Turbuhaler. The mean age was 53 years, $73 \%$ were men, and the mean post-bronchodilator $\mathrm{FEV}_{1}$ was $80 \%$ of predicted. There was a significant initial effect of inhaled budesonide on lung function. In the first 6 months the placebo group experienced a rapid decline in $\mathrm{FEV}_{1}$ of $81 \mathrm{ml} / \mathrm{year}$, whereas the budesonide group had an increase in $\mathrm{FEV}_{1}$ of $17 \mathrm{ml} /$ year. From 9 to 36 months both groups had a decline in $\mathrm{FEV}_{1}$ : $69 \mathrm{ml} /$ year in the placebo group and $57 \mathrm{ml} /$ year in the budesonide group; the difference was not statistically significant $(\mathrm{p}=0.39)$. After substratification according to pack-years of smoking there was a tendency towards an effect of budesonide in subjects with $\leqslant 36$ pack-years but the difference in decline from 9 to 36 months still did not reach statistical significance. No effect was seen on exacerbation rate.

The Inhaled Steroids in Obstructive Lung Disease in Europe (ISOLDE) study ${ }^{3}$ is the only one which has included patients with moderate to severe COPD, the mean $\mathrm{FEV}_{1}$ being $50 \%$ of predicted. A total of 751 patients were included and randomised to either fluticasone $500 \mu \mathrm{g}$ or placebo in a metered dose inhaler via a Volumatic spacer twice daily. After randomisation all patients were immediately offered 2 weeks of treatment with oral prednisolone, $0.6 \mathrm{mg} / \mathrm{kg}$ once daily. The main effect parameter was decline in $\mathrm{FEV}_{1}$ and the secondary effect parameters were exacerbations, symptoms, and health status evaluated using the St George Respiratory Health Questionnaire (SGRQ). Only 219 patients in the fluticasone group and 182 in the placebo group completed the study; patients with more than three exacerbations within a 3 month period were excluded and this led to significantly more patients being excluded from the placebo arm. The course of lung function over the 3 years was almost similar to 
that seen in the EUROSCOP study except for the short term effect of oral prednisolone; the modelled declines in $\mathrm{FEV}_{1}$ were $50 \mathrm{ml} /$ year in the fluticasone group and $59 \mathrm{ml} /$ year in the placebo group. There was an overall reduction in number of exacerbations from 1.32 to 0.99 per year $(p=0.03$, table 1$)$. Most significantly, the gradual loss in health status was slower in the fluticasone group: 3.2 units per year in the placebo group compared with 2.0 units per year in the fluticasone group $(\mathrm{p}=0.004)$. This decline, however, may not be representative of the normal decline which occurs in patients with COPD because it was preceded by an oral steroid trial, and it has been shown that such a trial substantially enhanced health status. ${ }^{50}$ Hence, the decline after a steroid trial will at least be partly due to withdrawal of steroids.

Finally, the Lung Health Study II has been published and confirms the findings of the previous studies. ${ }^{4} \mathrm{~A}$ total of 1116 patients with mild to moderate COPD were randomised to either triamcinolone $1200 \mu \mathrm{g}$ or placebo in this multicentre trial including 10 clinical centres in the USA and Canada. As in the previous studies, no effect of inhaled steroids was seen on the decline in $\mathrm{FEV}_{1}$ (mean (SD) decline of 47 (3) ml/year in the placebo group and 44 (2.9) $\mathrm{ml} /$ year in the triamcinolone group). The effect increased somewhat with increasing compliance. The exacerbation rate was not considered specifically but there were fewer unscheduled visits to doctors in the triamcinolone group.

Three recent 1 year studies ${ }^{731}$ have included a placebo arm and an arm receiving ICS. All have included patients more or less comparable to those included in the ISOLDE study. They have all been too short to provide data on the decline in $\mathrm{FEV}_{1}$, but an effect on the exacerbation rate was seen in all three studies of the order of $15-35 \%$ depending on the severity of the exacerbations. All the studies were too short to examine decline in health status.

Three meta-analyses of ICS in COPD have been published and, although more or less based on the same studies, they come to somewhat different conclusions. ${ }^{48-50}$ The first of these studies found no statistically significant effect of ICS on FEV whereas the most recent meta-analysis ${ }^{50}$ showed that ICS reduced the rate of decline in $\mathrm{FEV}_{1}$ by $7.7 \mathrm{ml} /$ year (95\% CI 1.3 to 14.2). In high dose studies the effect was even larger: $9.9 \mathrm{ml} /$ year (95\% CI 2.3 to 17.5 ). Figure 1 summarises the results of this meta-analysis. Differences in values chosen for the analyses may explain some of the differences as the observed declines differ from the modelled declines in several studies. Would a true difference of $7.7 \mathrm{ml} /$ year matter? Probably, in itself, this difference is small; all large studies conducted to date have arbitrarily chosen $20 \mathrm{ml} / \mathrm{year}$ as the minimal relevant difference. However, given the heterogeneity of COPD, an overall difference of $7.7 \mathrm{ml} /$ year would indicate that groups of patients may experience a larger effect. Given the possible link between exacerbations and excess decline in $\mathrm{FEV}_{1}{ }^{42}{ }^{43}$ and the effect of ICS on exacerbation rate in patients with at least moderate COPD, it seems reasonable that the GOLD guidelines ${ }^{51}$ recommend ICS in patients with $\mathrm{FEV}_{1}<50 \%$ predicted and documented exacerbations.

Treatment with the combination of LABA and ICS (LABA/ ICS) improves symptoms and lung function and reduces exacerbations in patients with COPD (table 1). All three 1 year studies ${ }^{781}$ on the effect of LABA/ICS on FEV 1 show that the initial improvement is maintained over the year. The duration of the studies is insufficient to judge the effect of this combination therapy on the long term decline in $\mathrm{FEV}_{1}$. The results of longer term studies such as the TORCH study will have to be awaited before any firm conclusion can be made in this respect.
Combination treatment has a long term beneficial effect on health related quality of life. In the TRISTAN study ${ }^{7}$ only the combination group (salmeterol/fluticasone) showed a clinically significant improvement in SGRQ total score by week 52. There were statistically significant differences in SGRQ total score with the combination compared with both placebo and fluticasone alone assessed over the 52 weeks. These differences and the difference with placebo at the end of the trial were small and did not reach the minimal clinically significant difference. In the study by Szafranski et al the combination of formoterol/budesonide significantly improved the SGRQ total score. The difference with placebo just failed to reach the clinically meaningful level of four points. In the study by Calverley et $a l^{31}$ patients were initially treated with oral corticosteroids and formoterol before being randomised to four study treatments. At the end of the 12 month treatment period the SGRQ total score was 7.5 points lower in the formoterol/budesonide group than in the placebo group. This difference, however, is at least in part determined by the oral steroid trial performed before randomisation (see above).

A retrospective analysis of the UK General Practice Research Database has suggested that treatment with the combination of salmeterol/fluticasone might improve survival in patients with COPD. ${ }^{33}$ The ongoing TORCH study is investigating prospectively whether this combination therapy has an effect on all cause mortality in COPD.

\section{Antioxidants}

Oxidative stress has been implicated in the pathogenesis and progression of COPD. ${ }^{52-55}$ Both reactive oxidant species (ROS) from inhaled cigarette smoke and endogenously formed ROS by inflammatory cells constitute an increased intrapulmonary oxidant burden. Attenuation of oxidative stress would be expected to result in reduced pulmonary damage and a decrease in local infections, thus contributing to attenuation of the progression of COPD. At present the only antioxidant widely available for treatment in patients with COPD is $\mathrm{N}$ acetylcysteine (NAC). Its antioxidant properties and their relevance in relation to COPD have been recently reviewed. ${ }^{56}$

In an open observational survey in Sweden the decline in $\mathrm{FEV}_{1}$ in patients with COPD who took NAC for 2 years was less than in a reference group on usual care. ${ }^{57}$ This favourable effect was particularly apparent in patients over 50 years of age (annual decline in $\mathrm{FEV}_{1}$ of $30 \mathrm{ml}$ ) compared with the reference group (annual decline of $54 \mathrm{ml}$ ). After 5 years the decline in $\mathrm{FEV}_{1}$ in the NAC group was less than in the reference group (Lundbäck B et al, personal communication, 1993). Clearly, it should be noted that the nature of the study design precludes firm conclusions on the effect of NAC on lung function decline in COPD. In a multicentre, randomised, placebo controlled study (BRONCUS) in 523 patients, Decramer et $a l^{58} 59$ did not find an effect of NAC on the annual decline in $\mathrm{FEV}_{1}(54$ (6) $v 46$ (6) ml/year) but, after 3 years, functional residual capacity (FRC) was decreased in the NAC group $(-374 \mathrm{ml})$ but was slightly increased in the placebo group $(+8 \mathrm{ml}, \mathrm{p}=0.008)$. The significance of this effect on FRC, possibly related to a mucolytic effect on the small airways, still remains unclear. NAC did not affect the rate of decline in health status.

In a recent systematic review by Stey et $a l^{60}$ data on prevention of exacerbations, improvement in symptoms, and adverse effects were extracted from original reports. The relative benefit and number needed to treat were calculated for both individual trials and combined data. Thirty nine trials were retrieved; 11 (2011 analysed patients) published between 1976 and 1994 were regarded as relevant and valid according to preset criteria. Except for one study, these were placebo controlled, randomised trials. In nine studies 351 of $723(48.5 \%)$ patients receiving NAC had no exacerbation 


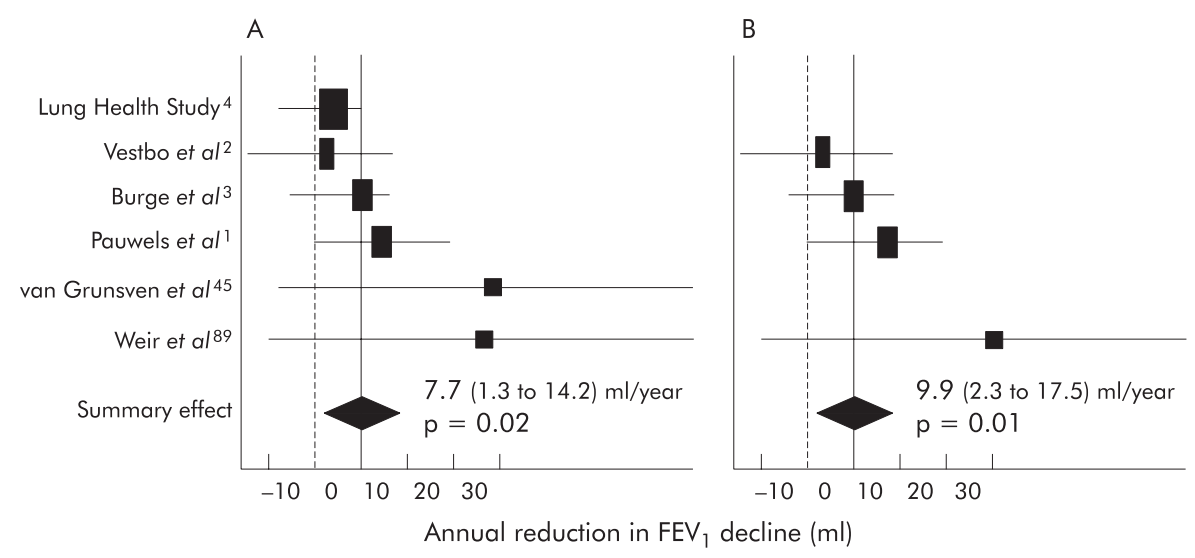

Figure 1 Meta-analysis of the effect of inhaled corticosteroids on the rate of decline in $\mathrm{FEV}_{1}$ in $(\mathrm{A})$ all trials and (B) trials in which a high dose of inhaled steroids was given. From Sutherland et al. ${ }^{50}$

compared with 229 of $733(31.2 \%)$ patients receiving placebo (relative benefit 1.56 (95\% CI 1.37 to 1.77 ); number needed to treat 5.8 ( $95 \%$ CI 4.5 to 8.1$)$ ). There was no evidence for any effect of study period (12-24 weeks) or cumulative dose of NAC on efficacy. In five trials 286 of 466 patients (61.4\%) receiving NAC reported improvement in their symptoms compared with 160 of 462 patients $(34.6 \%)$ receiving placebo (relative benefit 1.78 (95\% CI 1.54 to 2.05 ), number needed to treat 3.7 (95\% CI 3.0 to 4.9$)$ ).

These findings are in line with the outcomes of two previous meta-analyses using a less precise selection of studies $^{61}{ }^{62}$ and confirm that NAC has a clinically significant effect on the number and impact of exacerbations (table 1). It should be pointed out that the majority of the abovementioned studies were performed before ICS were widely used in COPD. In the abovementioned randomised study the annual exacerbation rate was not influenced by NAC but it decreased significantly by $22 \%$ in patients not taking ICS $(p=0.0396) .^{58} 59$ No effect was seen in patients taking ICS, indicating that the effects on the exacerbation rate do not appear to be additive. This is in line with the compilation of literature data shown in table 1 . As can be seen, the maximal effects possible appear to be around $25 \%$ and most interventions produce similar effects. No additive effects were observed between LABA and ICS, or between ICS and NAC.

\section{REHABILITATION}

Besides airflow obstruction, COPD has been characterised as a disease with significant systemic impact. ${ }^{63}{ }^{64}$ It is unknown how the systemic impact of the disease progresses over time. A few studies have looked at the decline in functional status in COPD. Three studies looked at the long term decline in walking distance. Bestall et a $l^{65}$ reported an annual decline in shuttle walking test of $23 \mathrm{~m}$ and Pinto-Plata et al ${ }^{66}$ reported a decline of $26 \mathrm{~m}$ in 6 minute walking distance (6MWD) in a group of patients followed up for 1.9 years. We found a decline of $25 \mathrm{~m} /$ year in 6MWD in patients followed up for 5.2 years. ${ }^{67}$ Consequently, it is expected that patients with COPD not submitted to rehabilitation programmes reduce their functional exercise capacity to a clinically relevant extent, $54 \mathrm{~m}$ every 2 years. ${ }^{68}$ This is in agreement with the reductions seen in health related quality of life, as observed in one large trial which investigated the effect of inhaled fluticasone in COPD. ${ }^{69}$ This decline, however, is likely to have been overestimated (see above).

Pulmonary rehabilitation programmes aim at tackling the systemic consequences of COPD. Exercise training programmes consistently improved health related quality of life and exercise tolerance. ${ }^{70}$ These changes are probably mediated through a significant improvement in skeletal muscle function. ${ }^{71-74}$ Changes are obtained after relatively short programmes but, especially in the more severe patients, longer programmes are needed. ${ }^{75}$ Although exercise training is considered the cornerstone of pulmonary rehabilitation programmes, ${ }^{76}$ these programmes have a comprehensive and multidisciplinary approach. Patients generally receive educational sessions and may receive psychological counselling, nutritional advice, occupational therapy, and self-management strategies may be practised..$^{78}$

The question whether pulmonary rehabilitation is capable of altering disease progression remains largely unanswered. Indeed, no studies have investigated the impact of long term rehabilitation programmes over a period of time long enough to address disease progression. In the only study in which patients were followed up for 6 years, no effects were seen of a short ( 8 week) pulmonary rehabilitation programme on disease progression estimated by rate of decline in lung function, exercise tolerance, health status, and mortality. ${ }^{78}$ However, pulmonary rehabilitation may, under certain conditions, theoretically impact on the disease progression.

Firstly, the decline in $\mathrm{FEV}_{1}$ is enhanced by exacerbations of COPD. $^{42}{ }^{43}$ Exacerbations further reduce muscle force ${ }^{6679}$ and health related quality of life. ${ }^{11}$ Pulmonary rehabilitation has been shown to reduce exacerbations ${ }^{80}$ and their severity significantly $^{81}$ (table 1). When self-management programmes are part of the rehabilitation package, hospital admissions are avoided. ${ }^{82}$ Hence, through a reduction in exacerbation rate and hospital admissions, pulmonary rehabilitation may indirectly affect disease progression.

Secondly, pulmonary rehabilitation aims at improving activities of daily living in COPD. Whether pulmonary rehabilitation is successful at achieving this goal is not well studied, but circumstantial evidence and small studies suggest that patients may have a more active lifestyle after pulmonary rehabilitation. ${ }^{83}{ }^{84}$ Since inactivity is one of the important contributors to skeletal muscle weakness ${ }^{64}$ and morbidity in $\mathrm{COPD}^{85}$ rehabilitation programmes leading to significant "reactivation" of patients may be effective in altering disease progression. As reactivation is a behavioural modification, it is likely that this occurs only after long term interventions or regular reinforcement. Studies using long term interventions, indeed, generally show long lasting effects on health related quality of life and functional exercise capacity. ${ }^{71} 8086$ We showed that 6 months of pulmonary rehabilitation improved 6MWD and health related quality of life and "stopped" the decline in both variables in the consecutive year of follow up. ${ }^{71}$ Shorter rehabilitation programmes lacking regular (e.g. weekly) reinforcement 
have, despite short term effects, more disappointing long term effects. ${ }^{87} 88$

\section{CONCLUSIONS}

The only treatment that was unequivocally shown to affect COPD progression is smoking cessation. Inhaled steroids may have a small effect on disease progression. Most treatments were clearly shown to offer symptomatic benefits. Several treatments reduce exacerbation rate by about $25 \%$ and may thus affect the progression of the disease. The effects of various treatments on exacerbation rate do not appear to be additive.

\section{ACKNOWLEDGEMENTS}

The authors acknowledge the expert secretarial assistance of Mrs C Ausseloos, Mrs E Lahousse and Mrs A Vandeborne.

\section{Authors' affiliations}

M Decramer, R Gosselink, T Troosters, Respiratory Division, University Hospital, Katholieke Universiteit Leuven, Leuven, Belgium

P Bartsch, Respiratory Division, CHU Liège, Belgium

C-G Löfdahl, Department of Respiratory Medicine and Allergology, Lund University Hospital, Lund, Sweden

W Vincken, Respiratory Division, Academic Hospital Vrije Universiteit Brussel, Brussels, Belgium

R Dekhuijzen, Department of Pulmonary Diseases, University Medical Centre Nijmegen, The Netherlands

J Vestbo, North West Lung Centre, Wythenshawe Hospital, Manchester, UK

R Pauwels, Department of Respiratory Diseases, Ghent University Hospital, Ghent, Belgium

R Naeije, Department of Pathophysiology, Erasme Campus of the Free University of Brussels, Belgium

This workshop was supported by GlaxoSmithKline-Belgium.

T Troosters is a postdoctoral fellow of the FWO-Vlaanderen.

\section{REFERENCES}

1 Pauwels RA, Lofdahl CG, Laitinen LA, et al. Long-term treatment with inhaled budesonide in persons with mild chronic obstructive pulmonary disease who continue smoking. N Engl J Med 1999;340:1948-53

2 Vestbo J, Sørensen T, Lange P, et al. Long-term effect of inhaled budesonide in mild and moderate chronic obstructive pulmonary disease: a randomised controlled trial. Lancet 1999;353:1819-23.

3 Burge PS, Calverley PMA, Jones PW, et al. Randomised, double blind, placebo controlled study of fluticasone propionate in patients with moderate to severe chronic obstructive pulmonary disease: the ISOLDE trial. BMJ 2000;320: 1297-303.

4 Lung Health Study Research Group. Effect of inhaled triamcinolone on the decline in pulmonary function in chronic obstructive pulmonary disease. N Engl J Med 2000;343:1902-9.

5 Vincken W, van Noord JA, Greefhorst APM, et al. Improved health outcomes in patients with COPD during 1 year's treatment with tiotropium. Eur Respir J 2002; 19:209-16.

6 Casaburi R, Mahler DA, Jones PW, et al. A long-term evaluation of once-daily tiotropium in chronic obstructive pulmonary disease. Eur Respir $J$ 2002;19:217-24

7 Szafranski W, Cukier A, Ramirez A, et al. Efficacy and safety of budesonide/ formoterol in the management of chronic obstructive pulmonary disease. Eur Respir J 2003;21:74-81

8 Calverley P, Pauwels R, Vestbo J, et al. Combined salmeterol and fluticasone in the treatment of chronic obstructive pulmonary disease: a randomised controlled trial. Lancet 2003;361:449-56.

9 Decramer M, Gosselink R, Rutten-Von Mölken M, et al. Assessment of progression of COPD: report of a workshop held in Leuven, 11-12 March 2004. Thorax 2005;60:343-9

10 Donaldson GC, Seemungal TA, Bhowmik A, et al. Relationship between exacerbation frequency and lung function decline in chronic obstructive pulmonary disease. Thorax 2002;57:847-52.

11 Spencer S, Jones PW, the GLOBE Study Group. Time course of recovery of health status following an infective exacerbation of chronic bronchitis. Thorax 2003:58:589-93.

12 Spencer S, Calverley PMA, Burge PS, et al. Impact of preventing exacerbations on deterioration of health status in COPD. Eur Respir $J$ 2004;23:698-702.

13 Spruit MA, Gosselink R, Troosters T, et al. Muscle force during an acute exacerbation in hospitalised patients with COPD and its relationship with CXCL8 and IGF-I. Thorax 2003;58:752-6.

14 Doll R, Peto R, Wheatley K, et al. Mortality in relation to smoking: 40 years observations on male British doctors. BMJ 1994;309:901-11.
15 Connett J, Kusek J, Bailey W, et al. Design of the Lung Health Study: a randomized clinical trial of early intervention for chronic obstructive pulmonary disease. Control Clin Trials 1993;14:3-19S.

16 Fletcher C, Peto R, Tinker C, et al. The natural history of chronic bronchitis and emphysema: an eight-year study of chronic obstructive lung disease in working men in London. London: Oxford University Press, 1976.

17 Centers for Disease Control. Mortality patterns - United States. Morbid Mortal Weekly Rep 1993:45:161-4.

18 Rennard S, Decramer M, Calverley PMA, et al. Impact of COPD in North America and Europe in 2000: subjects' perspective of the Confronting COPD International Survey. Eur Respir J 2002;20:799-805.

19 Mannino DM, Gagnon RC, Petty TL, et al. Obstructive lung disease and low lung function in adults in the United States: data from the National Health and Nutrition Examination Survey, 1988-1994. Arch Intern Med 2000;160:1683-9.

20 O'Hara P, Grill J, Rigdon MA, et al. Design and results of the initial intervention program for the Lung Health Study. Prev Med 1993:22:304-15.

21 Murray RP, Bailey WC, Daniels K, et al. Safety of nicotine polacrilex gum used by 3094 participants in the Lung Health Study. Chest 1996;109:438-45.

22 Kanner RF, Connett JE, Williams DE, et al. Effects of randomized assignment to a smoking cessation intervention in changes in smoking habits on respiratory symptoms in smokers with early chronic obstructive pulmonary disease: the Lung Health Study. Am J Med 1999;106:410-6.

23 Wise RA, Kanner RE, Lindgren $\mathrm{P}$, et al. The effect of smoking intervention and an inhaled bronchodilator on airways reactivity in COPD: the Lung Health Study. Chest 2003;124:449-58.

24 Anthonisen NR, Connett JE, Murray RP. Smoking and lung function of Lung Health Study participants after 11 years. Am J Respir Crit Care Med 2002; 166:675-9.

25 Murray RP, Anthonisen NR, Connett JE, et al. Effects of multiple attempts to quit smoking and relapses to smoking on pulmonary function. Lung Health Research Group. J Clin Epidemiol 1998;51:1317-26.

26 Connett JE, Murray RP, Buist AS, et al. Changes in smoking status affect women more than men: results of the Lung Health Study. Am J Epidemiol 2003;157:973-9

27 Wadbo M, Lofdahl CG, Larsson K, et al. Effects of formoterol and ipratropium bromide in COPD: a 3-month placebo-controlled study. Eur Respir J 2002;20:1138-46

28 Dahl R, Greefhorst LA, Nowak D, et al. Inhaled formoterol dry powder versus ipratropium bromide in chronic obstructive pulmonary disease. Am J Respir Crit Care Med 2001;164:778-84.

29 Boyd G, Morice AH, Pounsford JC, et al. An evaluation of salmeterol in the treatment of chronic obstructive pulmonary disease (COPD). Eur Respir J 1997; 10:815-21.

30 Jones PW, Bosh TK. Quality of life changes in COPD patients treated with salmeterol. Am J Respir Crit Care Med 1997; 155:1283-9.

31 Calverley PM, Boonsawat W, Cseke Z, et al. Maintenance therapy with budesonide and formoterol in chronic obstructive pulmonary disease. Eur Respir J 2003:22:912-9.

32 Liesker JJ, Van De Velde V, Meysman M, et al. Effects of formoterol (Oxis Turbuhaler) and ipratropium on exercise capacity in patients with COPD. Respir Med 2002;96:559-66.

33 Soriano JB, Vestbo J, Pride NB, et al. Survival in COPD patients after regular use of fluticasone propionate and salmeterol in general practice. Eur Respir J 2002;20:819-25

34 van Schayck CP, Dompeling E, van Herwaarden CL, et al. Continuous and on demand use of bronchodilators in patients with non-steroid dependent asthma and chronic bronchitis: four-year follow-up randomized controlled study. Br J Gen Pract 1995;45:239-44.

35 Johnson M, Rennard S. Alternative mechanisms for long-acting beta(2)adrenergic agonists in COPD. Chest 2001;120:252-70.

36 Eriefält I, Persson CG. Pharmacologic control of plasma exudation into tracheobronchial airways. Am Rev Respir Dis 1991;143:1008-14.

37 Mahler DA, Donohue JF, Barbee RA, et al. Efficacy of salmeterol xinafoate in the treatment of COPD. Chest 1999:115:957-65.

38 Dowling RB, Rayner CF, Rutman A, et al. Effect of salmeterol on Pseudomonas aeruginosa infection of respiratory mucosa. Am J Respir Crit Care Med 1997; 155:327-36.

39 Dowling RB, Johnson M, Cole PJ, et al. Effect of fluticasone propionate and salmeterol on Pseudomonas aeruginosa infection of the respiratory mucosa in vitro. Eur Respir J 1999;14:363-9.

40 Korn SH, Jerre A, Brattsand R. Effects of formoterol and budesonide on GMCSF and IL-8 secretion by triggered human bronchial epithelial cells. Eur Respir J 2001;17:1070-7.

41 Oostenbrink JB, Rutten-van Mölken MPMH, Al MJ, et al. One-year costeffectiveness of tiotropium versus ipratropium to treat chronic obstructive pulmonary disease. Eur Respir J 2004;23:241-9.

42 Kanner RE, Anthonisen NR, Connett JE. Lower respiratory illnesses promote $\mathrm{FEV}_{1}$ decline in current smokers but not ex-smokers with mild chronic obstructive pulmonary disease. Am J Respir Crit Care Med $2001 ; 164: 358-64$

43 Kerstiens HAM, Brand PLP, Hughes MD, et al. A comparison of bronchodilator therapy with or without inhaled corticosteroid therapy for obstructive airways disease. N Engl J Med 1992;327:1413-9.

44 Renkema TEJ, Schouten JP, Köeter $\mathrm{GH}$, et al. Effects of long-term treatment with corticosteroids in COPD. Chest 1996;109:1156-62.

45 van Grunsven PM, van Schayck CP, Derenne JP, et al. Long-term effects of inhaled corticosteroids in chronic obstructive pulmonary disease: a metaanalysis. Thorax 1999;54:7-14. 
46 Derenne JP. Effects of high-dose inhaled beclomethasone on the rate of decline in $\mathrm{FEV}_{1}$ in patients with chronic obstructive disease: results of a 2 yea prospective multicentre study. Am J Respir Crit Care Med 1995;151:A463.

47 Bourbeau J, Rouleau MY, Boucher S. Randomised controlled trial of inhaled corticosteroids in patients with chronic obstructive pulmonary disease. Thorax 1998:53:477-82

48 Highland KB, Strange C, Heffner JE. Long-term effects of inhaled corticosteroids on $\mathrm{FEV}_{1}$ in patients with chronic obstructive pulmonary disease. A meta-analysis. Ann Intern Med 2003;138:969-73.

49 Sin DD, McAlister FA, Man SF, et al. Contemporary management of chronic obstructive pulmonary disease: scientific review. JAMA 2003;290:2301-12

50 Sutherland ER, Allmers H, Ayas NT, et al. Inhaled corticosteroids reduce the progression of airflow limitation in chronic obstructive pulmonary disease: a meta-analysis. Thorax 2003;58:937-41.

51 Global Initiative for Chronic Obstructive Lung Disease (GOLD). Global strategy for the diagnosis, management and prevention of chronic obstructive pulmonary disease. NHLB/WHO workshop report, NIH publication 2701 Bethesda: US Department of Health and Human Services, 2001 (available at www.goldcopd.comrpar.

52 Repine JE, Lankhorst ILM, Debacker WA, et al. Oxidative stress in chronic obstructive pulmonary disease. Am J Respir Crit Care Med 1997; 156:341-57.

53 Rahman I, MacNee W. Lung glutathione and oxidative stress: implications in cigarette smoke-induced airway disease. Am J Physiol 1999;277:L1067-88.

54 MacNee W, Rahman I. Oxidants and antioxidants as therapeutic targets in chronic obstructive pulmonary disease. Am J Respir Crit Care Med 1999; 160:S58-65.

55 Dekhuijzen PNR, Aben KKH, Dekker I, et al. Increased exahalation of hydrogen peroxide in patients with stable and unstable COPD. Am J Respir Crit Care Med 1996; 154:813-6.

56 Dekhuijzen PNR. Antioxidant properties of $\mathrm{N}$-acetylcysteine: their relevance in relation to chronic obstructive pulmonary disease. Eur Respir 2004:23:629-36.

57 Lundbäck B, Lindström M, Andersson S, et al. Possible effect of acetylcystein on lung function. Eur Respir J 1992;5:289s.

58 Decramer M, Dekhuijzen PNR, Troosters T, and the BRONCUS Trial Committee, et al. The Bronchitis Randomised on NAC Cost-Utility Study (BRONCUS): hypothesis and design. Eur Respir J 2001;17:329-36.

59 Decramer M, Rutten-van Mölken MPMH, Dekhuijzen PNR, et al. Effects of Nacetyl-cysteine on outcomes in COPD. The Bronchitis Randomized on NAC Cost-Utility Study (BRONCUS). Lancet 2005 (in press)

60 Stey C, Steurer J, Bachmann S, et al. The effect of oral N-acetylcysteine in chronic bronchitis: a quantitative systematic review. Eur Respir J 2000; 16:253-62

61 Grandjean EM, Berthet P, Ruffmann R, et al. Efficacy of oral long-term Nacetylcysteine in chronic bronchopulmonary disease: a meta-analysis of published double-blind, placebo-controlled clinical trials. Clin Ther 2000;22:209-21.

62 Poole PJ, Black PN. Oral mucolytic drugs for exacerbations of chronic obstructive pulmonary disease: systematic review. BMJ 2001;322:1271-4.

63 Reid MB. COPD as a muscle disease. Am J Respir Crit Care Med 2001;164:1101-5.

64 ATS Working Group. Skeletal muscle dysfunction in chronic obstructive pulmonary disease. A statement of the American Thoracic Society and European Respiratory Society. Am J Respir Crit Care Med 2003;199:S1-40.

65 Bestall JC, Paul EA, Garrod R, et al. Longitudinal trends in exercise capacity and health status after pulmonary rehabilitation in patients with COPD. Respir Med 2003;97:173-80.

66 Pinto-Plata VM, Cote C, Cabral H, et al. The 6-min walk distance: change over time and value as a predictor of survival in severe COPD. Eur Respir 2004:23:28-33.

67 Troosters T, Probst V, Gosselink R, et al. Long-term decline in functional status is related to hospitalizations in COPD. Eur Respir J 2004;24:631s.
68 Redelmeier DA, Bayoumi AM, Goldstein RS, et al. Interpreting small differences in functional status: the six minute walk test in chronic lung disease patients. Am J Respir Crit Care Med 1997; 155:1278-82.

69 Spencer S, Calverley PM, Sherwood BP, et al. Health status deterioration in patients with chronic obstructive pulmonary disease. Am J Respir Crit Care Med 2001;163:122-8.

70 Lacasse Y, Brosseau L, Milne S, et al. Pulmonary rehabilitation for chronic obstructive pulmonary disease. Cochrane Database Syst Rev 2002;CD003793.

71 Troosters T, Gosselink R, Decramer M. Short- and long-term effects of outpatient rehabilitation in patients with chronic obstructive pulmonary disease: a randomized trial. Am J Med 2000;109:207-12.

72 O'Donnell DE, McGuire M, Samis L, et al. General exercise training improves ventilatory and peripheral muscle strength and endurance in chronic airflow limitation. Am J Respir Crit Care Med 1998;157:1489-97.

73 Sala E, Roca J, Marrades RM, et al. Effects of endurance training on skeletal muscle bioenergetics in chronic obstructive pulmonary disease. Am J Respir Crit Care Med 1999;159:1726-34

74 Maltais F, LeBlanc P, Simard C, et al. Skeletal muscle adaptation to endurance training in patients with chronic obstructive pulmonary disease. Am J Respir Crit Care Med 1996;54:442-7.

75 Salman GF, Mosier MC, Beasley BW, et al. Rehabilitation for patients with chronic obstructive pulmonary disease. J Gen Intern Med 2003;18:213-21

76 Lacasse Y, Guyatt GH, Goldstein RS. The components of a respiratory rehabilitation program: a systematic overview. Chest 1997;111:1077-88.

77 American Thoracic Society. Pulmonary rehabilitation: 1999. American Thoracic Society. Am J Respir Crit Care Med 1999;159:1666-82.

78 British Thoracic Society. Pulmonary rehabilitation. Thorax 2001;56:827-34.

79 Ries AL, Kaplan RM, Limberg TM, et al. Effects of pulmonary rehabilitation on physiologic and psychosocial outcomes in patients with chronic obstructive pulmonary disease. Ann Intern Med 1995;122:823-32.

80 Güell R, Casan P, Belda J, et al. Long-term effects of outpatient rehabilitation of COPD: a randomized trial. Chest 2000;117:976-83.

81 Griffiths TL, Burr ML, Campbell IA, et al. Results at 1 year of outpatient multidisciplinary pulmonary rehabilitation: a randomised controlled trial. Lancet 2000;355:362-8

82 Bourbeau J, Julien M, Maltais F, et al. Reduction of hospital utilization in patients with chronic obstructive pulmonary disease: a disease-specific selfmanagement intervention. Arch Intern Med 2003;163:585-91.

83 Bendstrup KE, Ingemann JJ, Holm S, et al. Out-patient rehabilitation improves activities of daily living, quality of life and exercise tolerance in chronic obstructive pulmonary disease. Eur Respir J 1997;10:2801-6.

84 Troosters $\mathrm{T}$, Gosselink R, Derycke $\mathrm{P}$, et al. Pulmonary rehabilitation improves activities of daily living (ADL), measured with a triaxial activity monitor. Am J Respir Crit Care Med 2002;165:A738

85 Garcia-Aymerich J, Farrero E, Felez MA, et al. Risk factors of readmission to hospital for a COPD exacerbation: a prospective study. Thorax 2003;258:100-5.

86 Swerts PM, Kretzers LM, Terpstra-Lindeman E, et al. Exercise reconditioning in the rehabilitation of patients with chronic obstructive pulmonary disease: a short and long-term analysis. Arch Phys Med Rehabil 1990;71:570-3.

87 Timms RM, Khaja FU, Williams GW, et al. Hemodynamic response to oxygen therapy in chronic obstructive pulmonary disease. Ann Intern Med 1985; 102:29-36

88 Ries AL, Kaplan M, Myers R, et al. Maintenance after pulmonary rehabilitation in chronic lung disease: a randomized trial. Am J Respir Crit Care Med 2003; 167:880-8.

89 Weir DC, Bale GA, Bright P, et al. A double-blind placebo-controlled study of the effect of inhaled beclomethasone dipropionate for 2 years in patients with nonasthmatic chronic obstructive pulmonary disease. Clin Exp Allergy 1999;29:125-8. 